\title{
Content Management System and Automation of Model Cloning Scalable EAV Model in GNEISYS Framework
}

\author{
C.Sundar, Shanthi.S, S. Kavya \\ \{ csr.mca@psgtech.ac.in, shanthiselvita@gmail.com, kavyaseerangasamy@gmail.com \}
}

Assistant professor (Sr.Grade), Computer Applications, PSG College of Technology, Tamilnadu, Coimbatore - 641004, India ${ }^{1}$,Master of Computer Applications, Computer Applications, PSG College of Technology, Tamilnadu, Coimbatore - 641004, India ${ }^{2}$,Master of Computer Applications, Computer Applications, PSG College of Technology, Tamilnadu, Coimbatore - 641004, India ${ }^{3}$

\begin{abstract}
The objective of this paper is to development of website based on content management system and to automate the array creation GNEISYS framework using new custom add-ons. The proposed work contains static pages and dynamic pages like news and events, gallery and enquiry form .It is about managing the website content, pages and menus dynamically by the framework and delivering output as Bootstrap based webpages. In this framework the processes are mainly handled by two primary engine files called Desk (D series) to Display Table Series and Form needs by F series. This is to provide the user scalable input types for getting inputs. This approach is for meeting the needs of multiple table information storage like parent-child table in EAV model
\end{abstract}

Keywords - Content management (CM), Content Management System - CMS, DDesk/table,F- Form, GNEISYS, Automate, Array creation,D series, F series, EAV model

\section{Introduction}

CMS helps to dynamically add the contents pages menus to the website. CMS in turn uses D Series and F series to load the contents. The input is been given in F series which will be processed and stored in database and the output is display as D series. CM refers to the procedures and technology that enable the gathering, management, and dissemination of information in any form or medium. Text or documents, multimedia files (such as audio or video files), or any other file type with a content lifetime that must be handled might be considered content. Content management is a collaborative effort by definition. The need for this paper is to avoid the duplication of the existing code infrastructure and also to standardize the structure of a data in terms of arrays. This will avoid the confusions of adding or modifying the existing functionalities and to avoid overlapping by cloning those data while creation and with some standard templates and regenerates that data in a structured array.

\section{About Gneisys Framework}

Gneisys is a information system framework that facilitates the BREAD (Browse, Read, Edit, Add, Delete) functionality. This framework is based on continuous improvement for real time problems and feedback. This framework gives the facility to build desk form based on definitions in Array structure. It is a content management framework that enables the use of reused components or customized applications for web 
content management. It is evolving in order to provide scalable, dependable, and effective solutions to changing demands. It has characteristics of both a web application framework and a content management system (CMS). The array structures in the input file are used to build the form. The forms in the input file will be used to produce the output. Both the input and output files are stored in the same file.

\section{Database}

To manage the database, it should be configured initially. The configuration of the database should be standardized to general format. The general format is managed by using the array structures. It is implemented by using PHP. It is also easily portable to other languages. The form is built using the array structures which is the input file. The output will be generated from the forms in the input file. Both the input as well as the output file resides in the same file. Users may collaborate with one another thanks to the Realtime database.

\section{Eav Model}

To describe entities, the entity-attribute-value (EAV) model uses a set of attributes (properties, parameters) that can be used to describe them, but the actual number of attributes that can be applied to a single item is quite small. In mathematics, this is known as a sparse matrix. EAV is also known as the object-attribute-value model, the vertical database model, or the open schema.

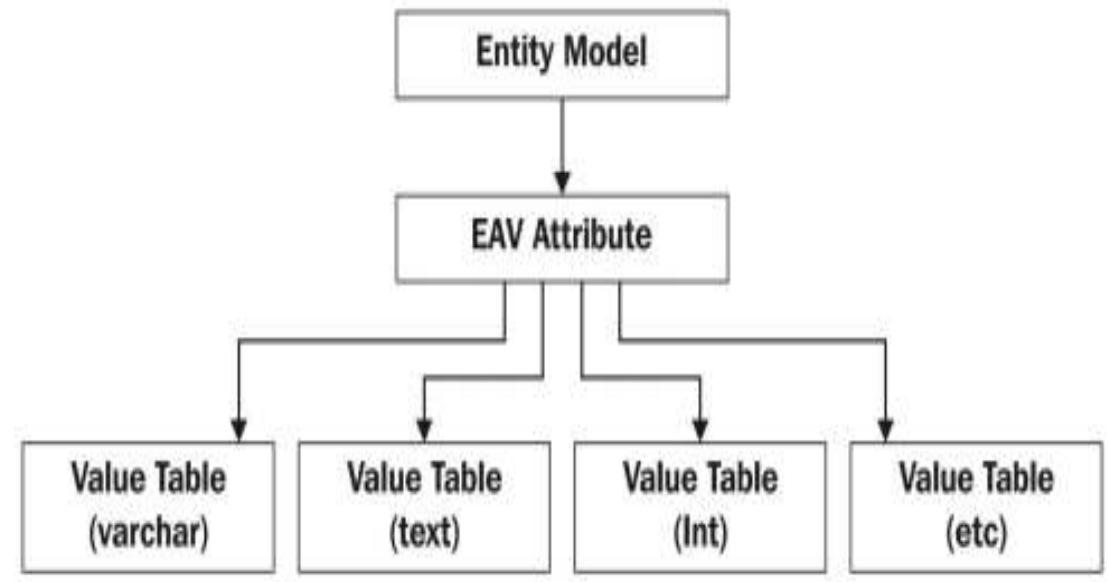

\section{Magento Stores each value type in different tables}

Fig 1.Entity Model

Fig 1 exemplifies how magento stores each value type in different tables using EAV model.

\section{Content Management System}

One of the most important aspects of a content management system (CMS) is the ability to manage all of a site's content from a single location. On the Internet, you'll find all sorts of documents and media files in various formats like HTML and XML. Publishing this content by hand would necessitate extensive technical expertise as well as time, as it would necessitate modifying and rearranging files on a file system exposed to the internet via a web server. Content management systems store the actual content, such as text or images, in a database. 
Based on the guidelines, the system then automatically extracts the material and displays it on the relevant pages. Content management systems were designed to assist individuals in publishing papers and media with less technological involvement and in a more uniform and automated manner.

A website wireframe, also known as a page schematic or screen blueprint, is a graphical representation of a website's skeleton architecture. The word "wireframe" is derived from other areas that employ a skeleton structure to depict 3-dimensional shape and volume. This wireframe diagram was created using the web tool diagram.io.

\section{Existing Work}

In the current system, there is no responsive web designs, and it always takes time. Many hours and dollars are spent managing static material, especially on sites with hundreds or thousands of pages. Sites are expanding and becoming increasingly content-rich. Successful websites amass massive amounts of material in a short period of time. \& maintaining Consistency in Content: The design of pages and the style of the site are intrinsically tied with the content itself - to update material, persons with HTML knowledge are required, or mistakes and style issues would occur. It's also challenging to keep the material up to date.

\section{Proposed Work}

In proposed system the web pages can be managed dynamically by CMS with the help D and F series. The System gives features to add new pages, new menu and galleries. It has specified users and roles for users to employ in order to add, delete, or edit material on the website. Each user has the ability to edit data based on his or her access privileges. Only the administrator may give roles to users and has complete control over each user's behavior.

i. Quick and easy page management - An authorized user may quickly and simply publish online without the need for complex software or programming.

ii. Flexibility for developers - Since it allows non-technical users to readily post material, technical developers are free to focus on functionality and increased features.

iii. Design is distinct from content, making it simple to modify information without concern of inadvertently altering the design.

iv. Database-driven - need to change data once for it to be updated throughout your site.

v. Mobile ready - It adapts your site automatically to accommodate tablets, mobile devices, and smaller browser windows. 


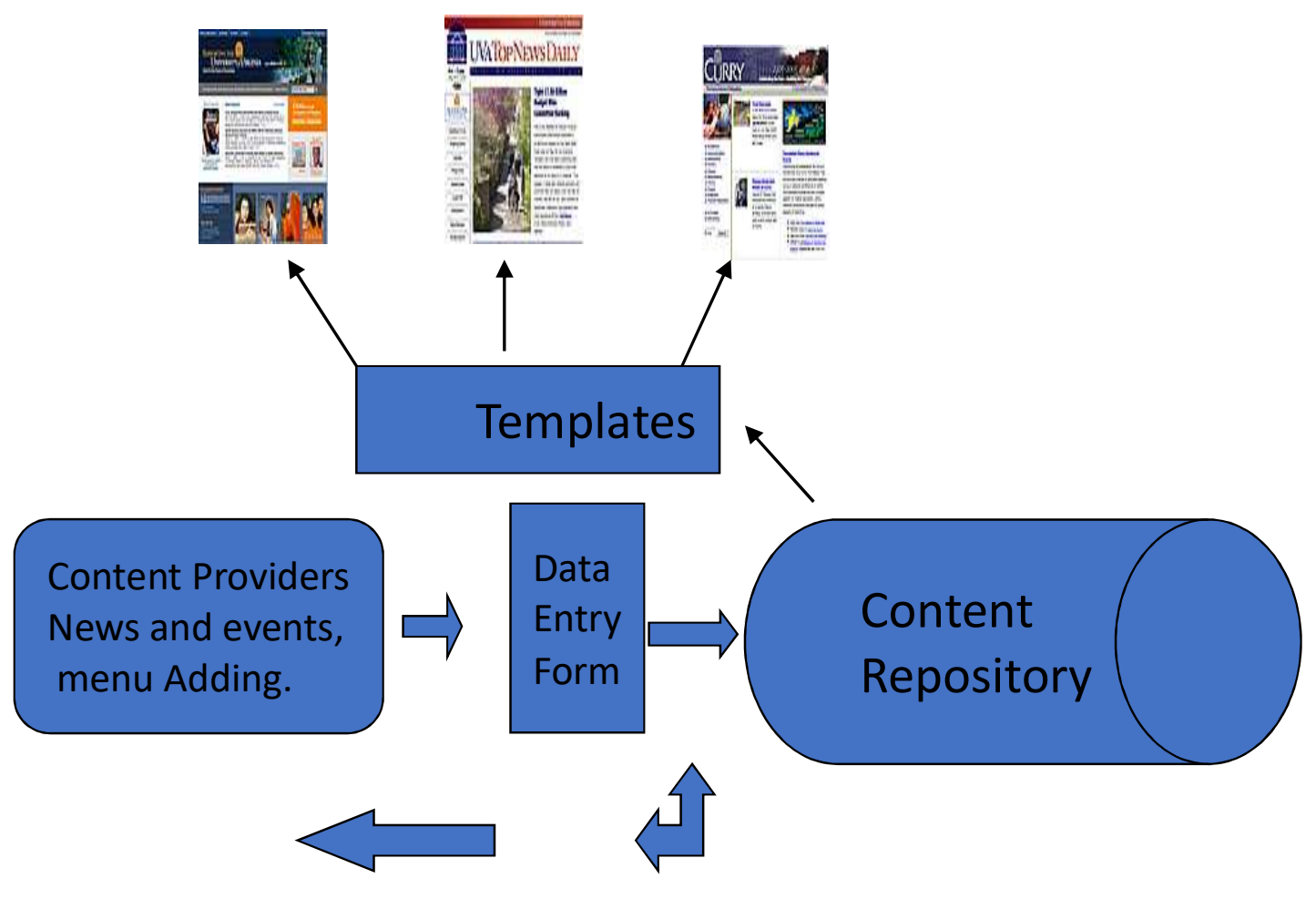

Fig 2 Block Diagram

Figure 2 depicts the overall flow of the system..

\section{Technology Overview}

HTML

Hyper Text Markup Language (HTML) is the abbreviation for HTML. Linkages between online pages are known as "hypertext," and the term refers to both those within a single website and those between websites. HTML tags transform the text they contain into links, which are an essential part of the Web Markup. It is possible to include HTML tags and plain text in a single HTML file The content of a static HTML page is always the same. The editor must be familiar with HTML in order to make changes to the content.

\section{CSS}

Included in style sheets are rules that govern the application of styles. Selections and declarations are the building blocks of these rules. CSS is in charge of the look and feel of a web page. To name a few things that CSS can control: the colour and style of the text; fonts; the spacing between paragraphs; the 
size of columns; background images or colours; layout designs; differences in display for different devices and screen sizes.

Simple to grasp, CSS gives you tremendous control over the visual appearance of an HTML document. The markup languages HTML and XHTML are the most common ones with which CSS is used.

\section{PHP}

As a server-side scripting language, PHP has a wide range of applications, including web development as well as general-purpose software development. Web frameworks and other template engines can also be used in conjunction with PHP code. Because it is a server-side scripting language, it aids in the transmission of data for storage in a database. Arrays can include items of any kind that PHP supports, such as resources, objects, and even other arrays. Order is retained in lists of values as well as hashes containing both keys and values, which can be mixed. PHP incorporates or uses a number of free and open-source libraries in its source distribution or in the final PHP binary builds.

\section{Testing}

A series of testing are performed for this application.

\section{A. UI Testing}

This way of approach ensure that the elements of UI like toolbar, menu, image, list in the application work consistently across all the target platform and the layout, resolution remains as expected. On a whole it provides better usability experience.

\section{B. Test Cases}

When a system is tested, a set of actions are taken to see if it meets the software specifications and functions properly.

\begin{tabular}{|c|c|c|c|c|}
\hline Sl.no & $\begin{array}{l}\text { Conditions to be } \\
\text { checked }\end{array}$ & Expected result & Observed Outcome & Status \\
\hline 1 & $\begin{array}{l}\text { All fields must be non- } \\
\text { empty }\end{array}$ & $\begin{array}{l}\text { All fields must be filled } \\
\text { with relevant data }\end{array}$ & $\begin{array}{l}\text { Display the error } \\
\text { message "Please fill all } \\
\text { the required fields" }\end{array}$ & Pass \\
\hline 2 & $\begin{array}{l}\text { Username must be } \\
\text { unique }\end{array}$ & $\begin{array}{l}\text { It must throw an error } \\
\text { message if the user has } \\
\text { already registered or the } \\
\text { username exists. }\end{array}$ & $\begin{array}{l}\begin{array}{l}\text { Displays } \\
\text { "Username } \\
\text { exists" }\end{array} \\
\text { already }\end{array}$ & Pass \\
\hline 3 & $\begin{array}{l}\text { Checking for email } \\
\text { whether it contains @ } \\
\text { symbol }\end{array}$ & $\begin{array}{l}\text { It must throw an error } \\
\text { message if the email does } \\
\text { not contain an @ symbol }\end{array}$ & $\begin{array}{l}\text { Displays the error } \\
\text { "Invalid Email" }\end{array}$ & Pass \\
\hline 4 & $\begin{array}{l}\text { Check the password limit } \\
\text { whether at least } 6 \\
\text { characters have been } \\
\text { entered }\end{array}$ & $\begin{array}{l}\text { It must throw an error } \\
\text { message if the requested } \\
\text { pattern is not matched }\end{array}$ & $\begin{array}{l}\text { Displays the error } \\
\text { "Password pattern is not } \\
\text { matched" }\end{array}$ & Pass \\
\hline
\end{tabular}




\begin{tabular}{|l|l|l|l|c|}
\hline 5 & $\begin{array}{l}\text { Checking for 10 numeric } \\
\text { characters in phone } \\
\text { number field }\end{array}$ & $\begin{array}{l}\text { The registration process } \\
\text { must be successful if it } \\
\text { satisfies all of the above } \\
\text { mentioned requests and } \\
\text { contains 10 digit numeric } \\
\text { pattern in the phone } \\
\text { number field. }\end{array}$ & $\begin{array}{l}\text { The user is validated } \\
\text { against the registration } \\
\text { constraints and then } \\
\text { taken to the login Page }\end{array}$ & Pass \\
\hline
\end{tabular}

\section{Conclusion}

This proposed system helps to deal with the websites which maintains vast amount of data which handles the content dynamically. It has the important functions like separation of layout and content, editor and managing the workflow for the content. This model will help the developers to manage their code in a structured manner and also it will avoid the overlapping and the duplications of the software. To satisfy future demands, which may grow progressively more complicated, the system's efficiency can be increased by making changes to the project. Its future work focuses on developing mobile apps for data management in a compact format.

\section{ACKNOWLEDGEMENT}

We are thankful to Dr. K. Prakasan, Principal In-Charge, PSG College of Technology, Coimbatore for permitting us to take up this work. We extend our earnest gratitude to Dr A. Chitra, Professor and Head, Department of Computer Applications, PSG College of Technology, Coimbatore, for her support, encouragement and above all her ardent motivation.

\section{REFERENCES}

[1] Wikipedia. Content management, 2012. http://en.wikipedia.org/wiki/Content_management, accessed Dec. 2011.

[2] R.G. Dromey, How to solve it by computer, Pearson Publication.

[3] Robert D. Schneider, MySQL Database Design and Tuning

[4] Luke welling and Laura Thomson, PHP and MySQL Web development. 